\title{
Seismic Confinement Design for Rectangular Columns With Considering Shear Effect
}

\author{
Julio Cezar Haryantho ${ }^{1 *}$, Harun Alrasyid ${ }^{1}$, Pujo Aji ${ }^{1}$, Munarus Suluch ${ }^{1}$ \\ ${ }^{l}$ Civil Engineering Department, Institut Teknologi Sepuluh Nopember, Surabaya, Indonesia \\ *Corresponding author: juliocezarharyantho@gmail.com
}

\begin{abstract}
This research discusses the role of transverse reinforcement as seismic reinforced concrete columns confinement. The latest confinement design addressed for columns remains standing under certain level of axial compression and displacement demands. However, this purpose did not consider shear effect. An approach formulation to determine the amount of confinement for reinforcement concrete that account effect of shear is provided. This method is based on combined effects of axial and shear stress that found in coulomb failure criterion. The proposed formulation are tested in 163 column test result data base and compared with several building codes. The result showed that the formulation can reduce amount of confinement safely for most columns.
\end{abstract}

Keywords—confinements, coulomb criterion, reinforced concrete columns.

\section{INTRODUCTION ${ }^{1}$}

$\mathrm{T}$ here is a lot of great country that is susceptible to ground motion or earthquake which is directly indicate that the effect of the earthquake also cannot be ignored in case of building structure. One of the factor that holds building structure's resistance to earthquake is transverse reinforcement. Studies shows that good transverse reinforcement will also results in good building structure that resist earthquake. It needs to know that the function of transversal reinforcement in reinforcement concrete is to resist shear, holds the buckling in longitudinal reinforcement and gives confinement to core of reinforce concrete column.

The essential principal for a reinforce concrete column that subjected to strong ground motion such as earthquake is that it still sustain an important portion of its strength as it experiences reversible loading even until reach nonlinear response. It indicates that there is still a lot of complex interaction that need to be noticed in term resistance of reinforce concrete column to earthquake such as the magnitude of normal stresses and shear stresses, drift history, the strength and type of concrete, and transversal reinforcement (distribution, strength, and configuration). The main point to determine the behavior of the column is the transversal reinforcement because the other like the dimension and the strength is commonly determined by the design issues.

Recently transversal reinforcement criteria design commonly refers to two main concept of column behavior Blume et al [1]. First concept refers to rotation capacity at the area of potential hinge region which is usually assume near ends of the column. The shear failure will be referred to the second concept. This two concept is emerged based on the interaction between theory and practical but not related each other.
It is a basic to know that transverse reinforcement has three main purpose regarding its role in reinforced concrete members as: (1) prevent shear failure in the members; (2) avoid longitudinal bar from buckling; (3) Confine concrete column core. When diagonal tension cracks occurred and cover concrete spalled, these function start to take action. For example the ACI 318-11 [2] confinement design of which the equation based on research of Richart, Bradtzaeg [3] developed to assure column stand still under axial compression after cover of the concrete spalled. The ratio of gross area of the column section to the area of the concrete core also the specified concrete compressive strength to specified yield strength are two main point of this confinement requirement.

Some former researchers perform experimental study and evaluate ACI 318-11 [2] confinement provision. Based on the research above then emerge some limitation such as (1) effect of axial load level do not take account for confinement requirements; (2) confinement demand do not include deformation parameters; (3) confinement provision do not consider the utility of high-strength materials. Design equation that consider the effect of high-strength concrete, confinement effeteness, and deformation demand represented by one confinement design equation that added in ACI 318-14 [4] to cover this weakness. However, this additional confinement design equation at ACI 318-14 [4] has not been assessed through experimental and analytical study.

In this research an approach formulation to determine the amount of confinement reinforcement concrete that take account the effect of shear is provided. The propose confinement formulation will be evaluated using 163 data experimental of rectangular reinforced concrete columns. The performance of this proposed formulation will be compared with the other building code such as ACI 3182011 [2], ACI 3182014 [4], CSA A23.3 [5], NZS 3101 [6], ITG 4.3R [7], and Elwood [8]. Need to be noticed that the proposed formulation will restricted to rectangular confinement only. 


\section{METHOD}

The formulation of proposed equation is modifying method of Pujol et al [9] which is this method suggested the formulation to determine the amount of transverse reinforcement should be based on direct combination between the normal stresses and shear stresses. Failure condition of material which is weak in tensile force under shear $(\tau)$ and normal stresses $(\sigma)$ in one plane will be correctly represented in failure criterion proposed by Coulomb [10]. This criterion can predict the strength of the concrete core of a column under displacement reversal. Coulomb's criterion can be illustrated in Figure 1.

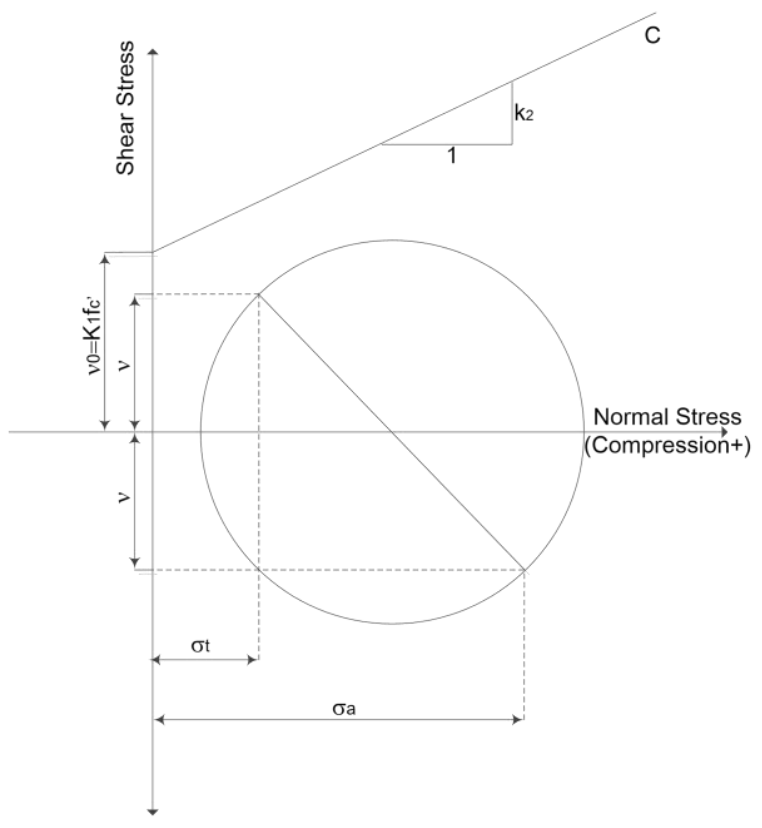

Figure 1. Coulomb's Criterion (Pujol [9])

It needs to know that Mohr's circle represents the combination of axial and shear stresses of material. Mohr's circle also represents the state of equilibrium. Failure is assumed to occur when the Mohr's circle intersects line $\mathrm{C}$, where line $\mathrm{C}$ described as:

$v_{u}=v_{0}+m \sigma$

Where $V_{u}=$ unit shear strength; $V_{0}=$ ordinate of line representing Coulomb's criterion at $\sigma=0 ; m=$ slope of line representing Coulomb's criterion; and $\sigma=$ unit stress acting perpendicular to the potential failure plane.

Mohr's circle represents the average stresses in the column core. This average stresses are form of axial stresses taken as:

$\sigma_{a}=\frac{P+T}{h_{c} b_{c}}$

While unit shear stress calculated as:

$\tau=\frac{V}{h_{c} b_{c}}$

For the stresses on transversal reinforcement can be calculated based on the property of transversal reinforcement as:
$\sigma_{t}=\frac{A_{v} f_{y t}}{h_{c} b_{c}}$

Where $\sigma_{a}=$ mean axial compressive stress on the core; $P$ $=$ applied axial load; $T=$ tensile reinforcement force $(1 / 2$ $\left.A_{s} f_{y}\right) ; h_{c}=$ depth of core; $b_{c}=$ width of core; $\sigma_{t}=$ mean stress exerted on the concrete by the hoop bars assumed to be yield; $A_{v}=$ cross sectional area of hoop bars; $F_{y t}=$ transverse reinforcement yield stress; $s=$ spacing of transverse reinforcement; $\tau=$ mean shear stress; $V=$ maximum shear force.

There is very few information available about the constants in equation (1) but the research of Richart et al [11] has defined coulomb criterion relative to concrete strength as:

$v_{u}=k_{1} f_{c}^{\prime}+k_{2} \sigma$

With using data from test of concrete confined by hydraulic pressure and he came with conclusion of value $k_{1} \approx 1 / 4$ and $k_{2} \approx 1 / 4\left(\mathrm{k}_{1}\right.$ relate to cumulative effect of micro crack and $\mathrm{k}_{2}$ relate for normal weight concrete loaded with increasing monotonic load).

Pujol et al [9] hypothesized that only $k_{l}$ is susceptible to be changed because relate to cumulative effects of micro cracks resulted from interaction number and drift of loading cycle. It is reasonable that the subsequent loading in the same direction will produce additional internal cracking of concrete and may reduce the strength by finite amount. that's why the reduction in $k_{l}$ is interpreted in relation to displacement. Pujol et al [9] relate $k_{l}$ value with $\gamma / \lambda$ (where $\gamma=$ maximum drift ratio at $20 \%$ reduction of maximum lateral strength; $\lambda=$ the ratio of the shear span to the effective depth) was found suitable for normalizing drift capacity data from reinforce concrete members subjected to cyclic shear.

Later Pujol et al [9] propose lower bound for $k_{l}$ value based on data from 29 test of reinforce concrete columns. This $\mathrm{k}_{1}$ value then used to formulate the amount of transverse reinforcement which the formula derivation can be explain as:

Formulate radius of Mohr circle $(R)$ at failure as a function of $v_{0}, \sigma_{a}, \sigma_{t}$, and $\phi=\tan ^{-1}(m)$ :

$R=v_{0} \cos \phi+\frac{1}{2}\left(\sigma_{t}+\sigma_{a}\right) \sin \phi$

Express $R$, the radius of mohr circle "at failure" as a function of $v, \sigma_{a}$, and $\sigma_{t}$ :

$R=\sqrt{\frac{1}{4}\left(\sigma_{a}-\sigma_{t}\right)^{2}+v^{2}}$

The calculated $\mathrm{k}_{1}$ can be determine by equating equation (6) and (7) also by replacing $\phi=\tan ^{-1}(3 / 4)$ and $v_{0}=$ $k_{l} . f c^{\prime}$ :

$k_{1}=\frac{-\frac{3}{10}\left(\sigma_{a}+\sigma_{t}\right)+\sqrt{\frac{\left(\sigma_{a}-\sigma_{t}\right)^{2}}{4}+v^{2}}}{\frac{4}{5} f_{c}^{\prime}}$

Solving for $\sigma_{t}$ by equating equation (6) and (7) also replacing $\phi=\tan ^{-1}(3 / 4)$ :

$\sigma_{t}=\frac{3}{2} v_{0}+\frac{17}{8} \sigma_{a} \pm \frac{5}{8} \sqrt{\left[\left(4 v_{0}+3 \sigma_{a}\right)^{2}-16 v^{2}\right.}$

With taking minimum value of equation (9) and divided by $\sigma_{a}$ : 


$$
\frac{\sigma_{t}}{\sigma_{a}}=\frac{3}{2} \frac{v_{0}}{\sigma_{a}}+\frac{17}{8} \sigma_{a}-\frac{5}{8} \sqrt{\left[\left(4 \frac{v_{0}}{\sigma_{a}}+3\right)^{2}-16 \frac{v^{2}}{\sigma_{a}}\right]}
$$

By assuming $\alpha=4\left(v_{0} / \sigma_{a}\right)+3$ and $\beta=4\left(v / \sigma_{a}\right)$ equation (10) can be rewrite as:

$$
\frac{\sigma_{t}}{\sigma_{a}}=\frac{3}{2} \alpha+1-\frac{5}{8} \sqrt{\alpha^{2}-\beta^{2}}
$$

Substitute equation (4) to equation (11) will result in the formulation to determine the amount of transverse reinforcement which is written below:

$$
\frac{A_{s h}}{s b_{c}}=\frac{3}{2} \alpha+1-\frac{5}{8} \sqrt{\alpha^{2}-\beta^{2}} \frac{\sigma_{a}}{f_{y t}}
$$

In this research, the proposed formulation of transverse reinforcement base on experimental data about 163 reinforce concrete column with rectangular confinement. The range of the parameter on this data can be seen in Table 1 below: Table 1 .

\begin{tabular}{cccc}
\multicolumn{4}{c}{ Re seen ine of variable covered by experimental data. } \\
\hline PARAMETER & MINIMUM & MAXIMUM & AVERAGE \\
\hline$f_{y t}$, Mpa & 255 & 1424 & 550 \\
$f_{c}^{\prime}$, Mpa & 20.2 & 118 & 60.4 \\
s, mm & 25.4 & 229 & 77.5 \\
$A_{s h} / s b_{c}, \%$ & 0.11 & 3.43 & 1.15 \\
$A_{s h} / A_{g}, \%$ & 1.01 & 6.03 & 2.37 \\
$P / A_{g} f_{c}^{\prime}$ & 0.00 & 0.80 & 0.28 \\
\hline
\end{tabular}

The proposed formulation of transverse reinforcement is done with some modification on method by Pujol et al [9] such as:

Calculation of $k_{l}$ value will be done with correlation to drift ratio from data of 163 reinforce concrete column illustrated in Figure 2.

Relation between $k_{l}$ value a drift ratio can be formulated as:

$$
k_{1}=0.089-0.013 \delta \geq 0
$$

In this research, 3\% drift are used as displacement demand in evaluating confinement provision to the test data. This corresponds to the largest permissible maximum considered earthquake drift demand implied by ASCE [12]. Maximum considered demands are 1.5 times design basis demands, for which $2 \%$ drift limit is specified for the types of buildings that are likely to contain concrete columns. In order to satisfy the displacement target, the value of $k_{1}$ should be based on $3 \%$ drift. From equation (13) the value for $k_{l}$ for $3 \% \mathrm{drift}$ is 0.05 since the $k_{l}$ value are modified, the form of $\alpha$ are change into the following equation:

$\alpha=4 \frac{0.05 f_{c}^{\prime}}{\sigma_{a}}+3$

The modification formulation of Pujol et al [9] also by adding factor $k_{n}$, confinement effectivity factor and adding minimum amount of transverse reinforcement formula in the proposed confinement equation. The minimum confinement equation can be formulated as:

$$
\frac{A_{s h}}{s b_{c}} \min =0.09 \frac{f_{c}^{\prime}}{f_{y t}}
$$

$k_{n}=\left(\frac{n_{l s}}{n_{l s}-2}\right)\left(\frac{h_{x}+300}{500} \geq 1\right)$

With the modification which already mention before, the final proposed confinement equation can be written as follow:

$\frac{A_{s h}}{s b_{c}}=\frac{3}{8} \alpha+1-\frac{5}{8} \sqrt{\alpha^{2}-\beta^{2}} \frac{P}{A_{c h} f_{y t}} \geq 0.09 \frac{f_{c}^{\prime}}{f_{y t}}$

The formulation will be limited to $f_{y t} \leq 800 \mathrm{Mpa}$.

The result of confinement equation formula will be compare to the other building code to know its performance. The building code used to compare the performance is ACI 3182011 [2], ACI 3182014 [4], CSA A23.3-04 [5], NZS 3101 [6], ITG 4.3R [7], and Elwood [8].

Each building code has factors that make it special compare to other codes. But, for some code the high strength concrete is not considered in its formulation. Range of parameter of each building code can be seen in Table 2. Each building code has each differential formulation which is can be seen in Table 3 .

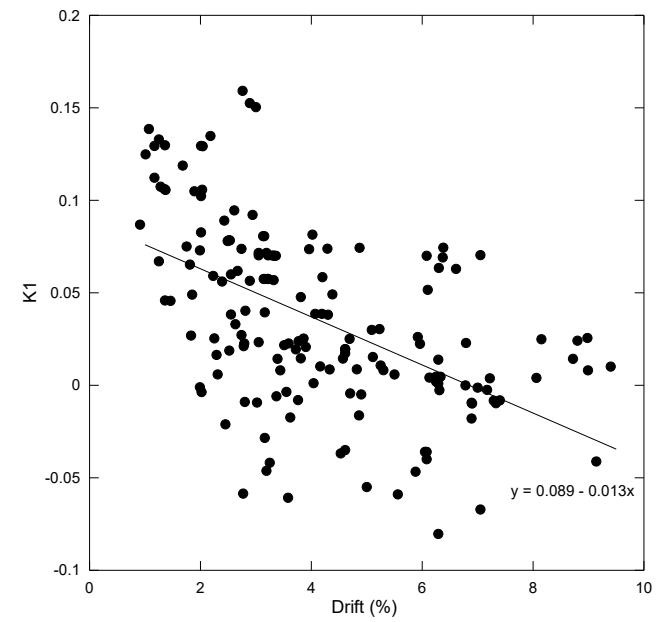

Figure 2. Graph of $\mathrm{k}_{1}$ value vs drift

Total of 163 experimental column data exist for running some examination to test the performance include proposed confine equation and the other building codes. The results will be presented in form of drift $(\%)$ vs $A s h_{\text {provided }} / A s h_{\text {code }}$ graph. The method to analyze each formula can be done by divide the data into quadrants illustrated in Figure 3 below:

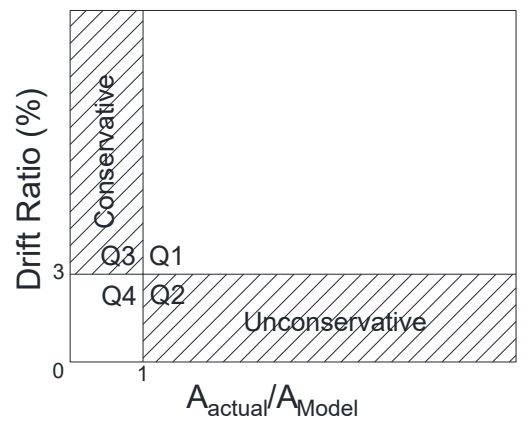

Figure 3. Graph for quadrant group

Confinement effectivity factor, $k_{n}$ can be written as: 


\begin{tabular}{|c|c|c|c|c|c|c|}
\hline \multirow[b]{2}{*}{ Model } & \multicolumn{5}{|c|}{ Additional Parameter } & \multirow[t]{2}{*}{ Notes } \\
\hline & $\begin{array}{l}\text { Axial } \\
\text { load } \\
\text { ratio }\end{array}$ & $\begin{array}{l}\text { Longitudinal } \\
\text { Reinforcement }\end{array}$ & $\begin{array}{l}\text { Confinement } \\
\text { effectiveness }\end{array}$ & $\begin{array}{l}\text { Deformation } \\
\text { Parameter }\end{array}$ & $\begin{array}{l}\text { High-strength } \\
\text { concrete } \\
\text { directly }\end{array}$ & \\
\hline ACI 318-11 & - & - & - & - & - & \\
\hline ACI 318-14 & $\mathrm{v}$ & - & $\mathrm{v}$ & $\delta_{u}=3 \%$ & $\mathrm{v}$ & Supported by column database \\
\hline CSA A23.3 & $\mathrm{v}$ & $\mathrm{v}$ & $\mathrm{v}$ & $\mu_{\phi}=16$ & - & $\begin{array}{c}\text { Moment Curvature, supported } \\
\text { by data experimental, and } \\
\text { column database }\end{array}$ \\
\hline NZS 3101-6 & $\mathrm{v}$ & $\mathrm{v}$ & $\mathrm{v}$ & $\mu_{\phi}=20$ & - & Moment Curvature \\
\hline ITG 4-3R07 & $\mathrm{v}$ & $\mathrm{v}$ & $\mathrm{v}$ & $\delta_{u}=2.5 \%$ & - & $\begin{array}{l}\text { Pushover, supported by data } \\
\text { experimental }\end{array}$ \\
\hline Elwood & $\mathrm{v}$ & $\mathrm{v}$ & $\mathrm{v}$ & $\delta_{u}=3 \%$ & & \\
\hline
\end{tabular}

Table 3.

Building code formulation comparison.

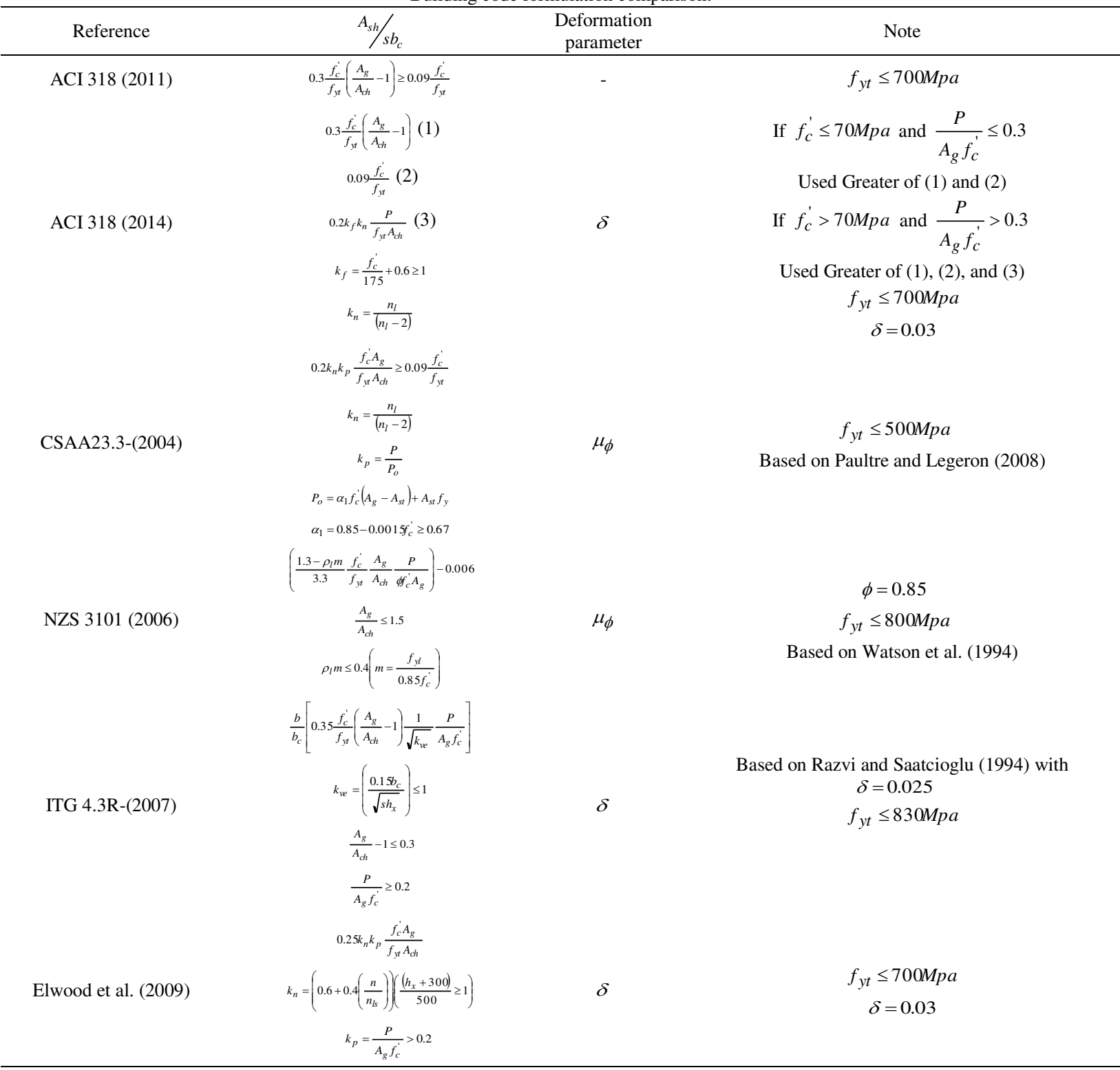

$A_{c h}$ : cross-sectional area of structural member measured out to out of transverse reinforcement; $A_{g}$ : gross area of column; $A_{s h}$ : total cross-sectional area of transverse reinforcement (including crossties) within spacing $\mathrm{s}$ and perpendicular to dimension bc; bc: cross-sectional area member core measured to outside edges of transverse reinforcement; $f_{c}^{\prime}$ : specified concrete strength; $f_{y l}$ : specified yield strength of longitudinal reinforcement ; $f_{y t}$ : specified yield strength of transverse reinforcement. ; hx: centre to centre spacing of longitudinal reinforcement laterally supported by corner of hoop or hook of crosstie: $\mathrm{m}:$ mechanical reinforcing ratio; $n_{l}$ :number of longidinal reinforcement laterally supporter by corner of hoop, or hook of crosstie; $\mathrm{p}$ : axial compression; $p_{u}$ :nominal axial load strength at eccentricity; s spacing of transverse reinforcement; $\rho_{l}$ : ratio of longitudinal reinforcement ; $\phi:$ capacity reduction factor $; \mu_{\phi}:$ curvature ductility ratio; $\delta$ : drift ratio.

the data into quadrants illustrated in Figure 3 below: From the graph then can be analyzed that the existing data divided to 4 quadrants that is quadrant 1 , quadrant 2, quadrant 3, and quadrant $4(\mathrm{Q} 1, \mathrm{Q} 2, \mathrm{Q} 3$, and Q4) which the naming according to figure 3 . The vertical line on the 
graph located on value 1 indicate the boundary between compliance and non-compliance of confinement requirement. The horizontal line point in value of $3 \%$ indicate performance target of ultimate drift at $20 \%$ reduction of lateral load. Column data located on Q1 refers to columns that satisfy confinement requirement and the drift capacity is same or more than drift target about $3 \%$. For columns that satisfy confinement requirement but not fulfills performance target will appear in Q2. This quadrant shows that confinement provision is unconservative. Column data not satisfy confinement requirement and also no fulfill performance target will locate in Q4. While column data which not fulfill confinement requirement but can satisfy drift target or performance target will appear in Q3 where this quadrant is called conservative quadrant because it require more reinforcement to achieve acceptable performance. From the explanation above can be conclude that the ideal model will locate in quadrant Q1 and Q4.

To make quantitative comparison form the models in scatter plot, using two statistic calculation for each code and model. The first following statistic are chosen to evaluate capability of each model to provide sufficient drift capacity calculated by value of $A$ that represent the presentation amount of column that satisfy model requirement and achieve drift ratio $\leq 3 \%$ or the function in terms of quadrant can be written as:

$$
A(\%)=\frac{Q_{2}}{Q_{1}+Q_{2}}
$$

The second statistic calculation to indicate degree of conservation of the model calculated by value $B$ that represent number of columns do not satisfy model requirement and achieve drift ratio $\leq 3 \%$ or in quadrant terms can be written as:

$$
B(\%)=\frac{Q_{4}}{Q_{3}+Q_{4}}
$$

Ideal model will give $A$ value of $0 \%$ or minimum to avoid over conservative, that is why value $B$ has to be maximized. The difference value between this two statistic will provide knowledge about performance of the model and as commonly good representation of model performance considering all column data.

$C=B-A$

Larger value of $C$ will produce more good result because it indicates safe model and yet not over conservative.

\section{RESULTS AND DISCUSSION}

The calculation method and the modification as already said before will obtain results which is represent in following graph grouped for each code of formula. The formula of proposed confinement equation will be labeled as proposed 1 .

From the graphs below show large different between one graph to another graph. For information the data of column grouped into category of axial load ratio. Overall, column data with axial load ratio $\leq 0.3$ has the most amount of data compare to the other group while column with axial load ratio $\geq 0.6$ has the least amount of data. Group column with axial ratio $\leq 0.3$ is the group with the most average high drift ratio even for some column the drift ratio can reach $9 \%$ also can be seen that the average this group of column have drift ratio above $3 \%$ while group of column with axial load ratio $\geq 0.6$ is the lowest average drift ratio even cannot reach $3 \%$ drift ratio. The group column with axial load ratio between 0.3 and 0.6 have drift ratio between two group which already said before.

The graph for model ACI 3182011 [2] can be inferred that the distribution is equally enough for each quadrant however most of the data located in Q3 while least data located in Q2. Also can be seen that the average column data that do not satisfy confinement reinforcement requirement $\left(A s h_{\text {provided }} / A s h_{\text {code }}<1\right)$ have more amount in quantity than the group that do not satisfy. It is very few data of column with axial load ratio $\leq 0.3$ that can satisfy transverse confinement requirement (Ash $h_{\text {provided }}$ $\left./ A s h_{\text {code }} \geq 1\right)$. Amount of data in Q3 and Q2 is much enough compare to Q1 and Q4 as ideal quadrant and it show not quite good results. Remember that the amount of Q1 and Q4 need to be more plentiful than Q2 and Q3. Also can be seen that there is no column with axial load ratio $\geq 0.6$ that can reach drift ratio $3 \%$.

For the Elwood [8] graph model, shows that in Q2 have very few data compare to other quadrant and it is a good sign because Q2 needed to as minimum as possible even 0. If compare to ACI 3182011 [2] model, this model produces very few data in Q4 the difference is drastic. From this model shows that there is much enough column data with axial load ratio $\leq 0.3$ that reach transverse confinement requirement (Ash $h_{\text {provided }}$ $\left./ A s h_{\text {code }} \geq 1\right)$. Also can be seen that the amount of column in Q1 and Q4 is much more than data column in Q2 and Q3 and it is a good sign.

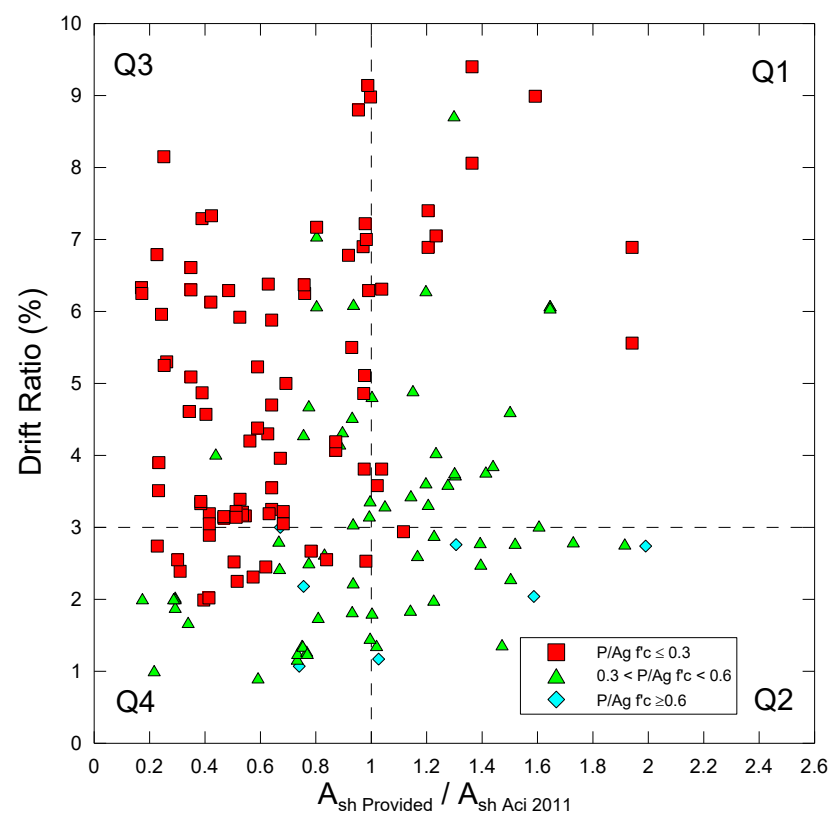

Figure 4. Drift Ratio Vs $A_{\text {sh Provided }} / A_{\text {sh }}$ ACI 3182011 
The Third International Conference on Civil Engineering Research (ICCER)

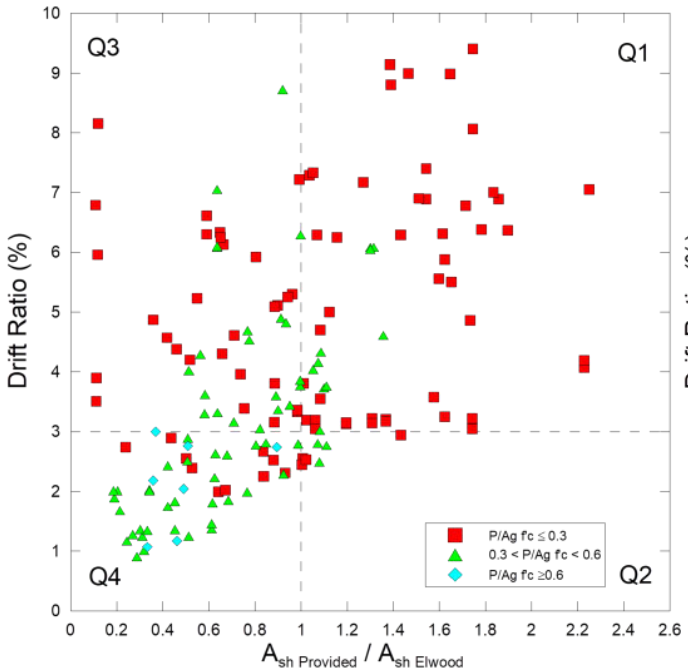

(b)

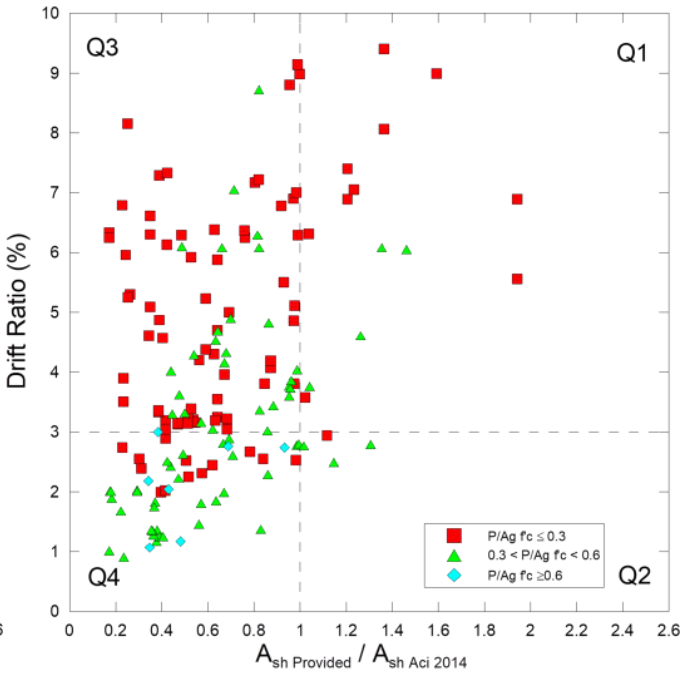

(b)

Figure 5. (a) Drift Ratio Vs $A_{\text {sh Provided }} / A_{\text {sh }}$ Elwood ; (b) Drift Ratio Vs $A_{\text {sh Provided }} / A_{\text {sh }}$ ACI 3182014

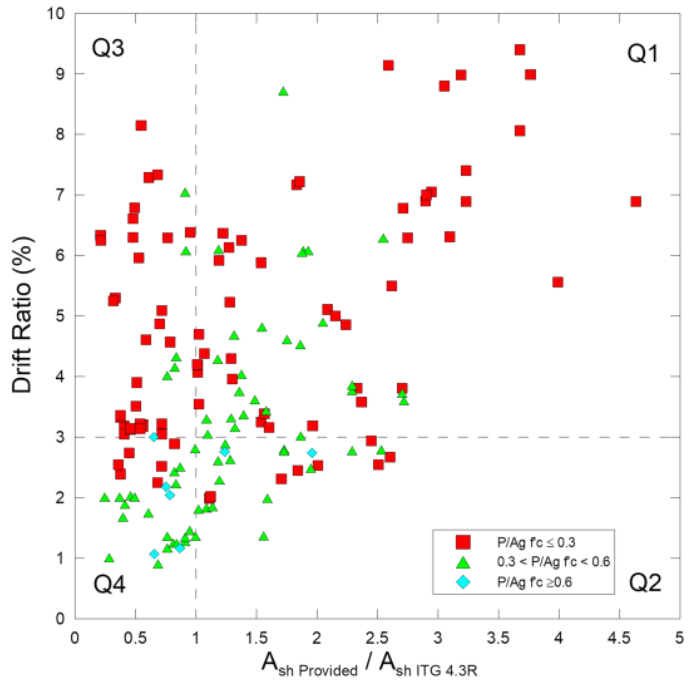

(a)

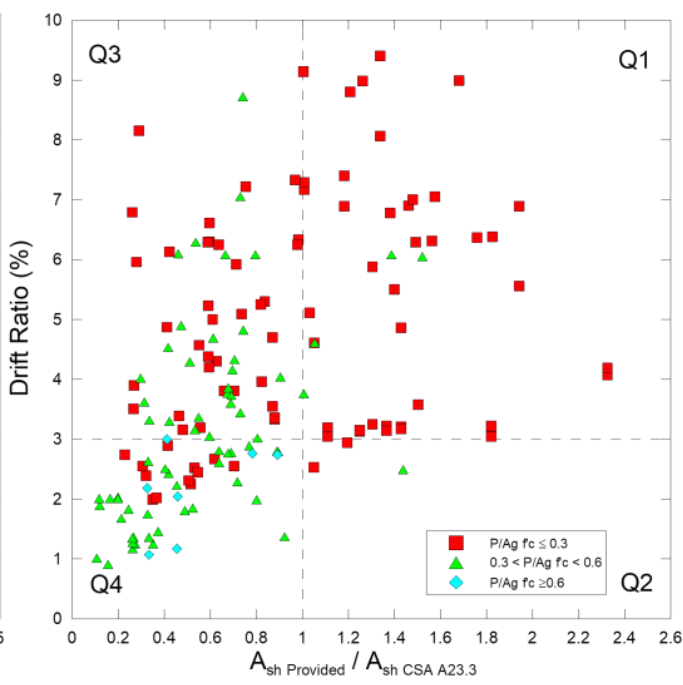

(b)

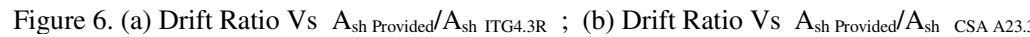

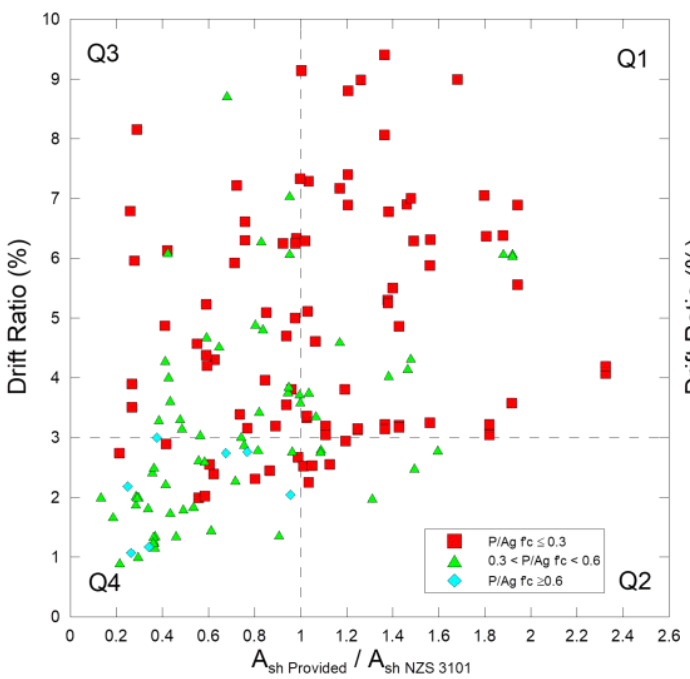

(a)

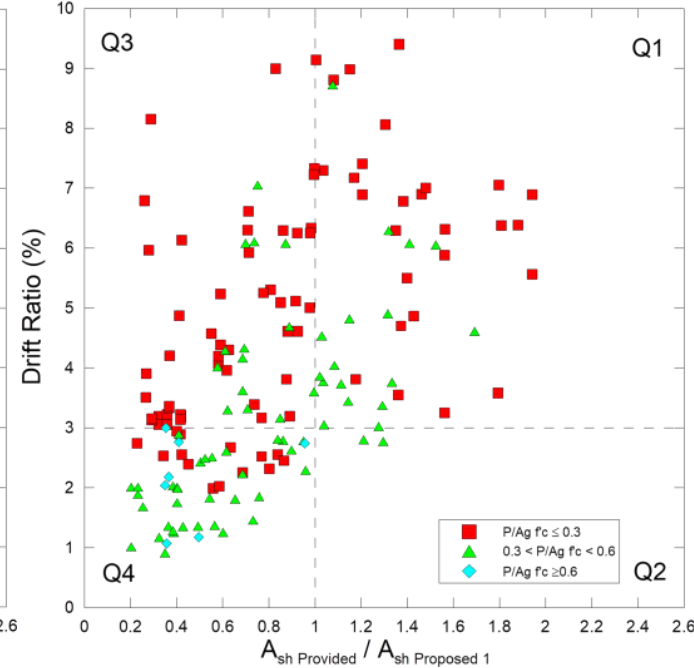

(b)

Figure 7. Drift Ratio Vs $A_{\text {sh Provided }} / A_{\text {sh NZs } 3101}$; (b) Drift Ratio Vs $A_{\text {sh Provided }} / A_{\text {sh }}$ Proposed 1 few data column quantities in Q2 and it is a good sign. 
Another important point is there is only few column data that satisfy transverse confinement requirement (Ash $\left.h_{\text {provided }} / A s h_{\text {code }} \geq 1\right)$ and this change is rather significance compared to the other former models. However, there is a lot of column located in Q3 only and it has much more column data than Q1 and Q4 and of course it is a bad sign.

The ITG 4.3R [7] graph model, can be seen that the pattern of this model is completely different with the other model which in this model there is a lot of column data that located in satisfy transverse confinement requirement area $\left(A s h_{\text {provided }} / A s h_{\text {code }} \geq 1\right)$. However, it results in increasing data located in Q4 compared to other models and it is not a good sign although column data in Q2 is the least column data amount compare to the other quadrant. The amount of column in Q3 also reduced significantly if compared to the other former models. The positive thing is that column data in quadrant Q1 and Q4 have much more data than quadrant Q2 and Q3 which shows that there is a lot of column that satisfy ITG 4.3R [7] confinement formula.

CSA A23.3 [5] graph model, the column data distribution pattern is similar to the other models with only 3 columns in quadrant Q2 which indicate as the least data compare to other quadrant. Also can be seen that most column data located in Q3. Positive facts that there is a lot of column data located in Q1 and Q4. The lowest drift ratio located in column with axial load ratio between 0.3 to 0.6 .

NZS 3101 [6] graph model shows that data column distribution spread equally between the four quadrants with consequent increasing data column in Q2. Also can be seen that amount of data in Q1 and Q4 are much more than Q2 and Q3.

Finally, for Proposed 1 graph model shows that distribution pattern in this model commonly similar to the other former models with very least column data in $\mathrm{Q} 2$ relatively to all the models. The positive thing is that there are many data columns located in quadrant Q1 and Q4 although quadrant Q3 hold the most amount of column data compare to other quadrants. The more amount of column data on Q1 plus Q4 more positive thing can be achieve such as indicate there is more column located in ideal zone. to be able to compare statically, the amount of column data for each quadrant will be calculated which illustrated in table 4 . Also the calculation of $A, B$, and $C$ value will be illustrated in table 4.

In table 4 , can be seen the distribution of column data for each quadrant and each models. Can be seen that the most minimum value of quadrant Q2 gained by proposed 1 model while the maximum value of quadrant Q3 achieved by ACI 3182014 [4] models. Also can be seen that for each value of $A, B$ and $C$ have already calculated. The value of $A$ expected to be as minimum as possible and the most minimum value of $A$ is held by proposed 1 model with value of 0.043 . While the value $B$ is expected as maximum as possible and the most maximum value of $B$ achieved by Elwood [8] model with value of 0.475 . To statically state that a model has better performance than the other is that it has to produce larger value of $C$. Proposed 1 models has the largest $C$ value compare to the other model the value is 0.4095 second largest value is CSA A23.3 [5] model with value of 0.3897. With this fact, it has been proved that model proposed 1 has the performance that better than any other model which means this model provide performance that is safe and yet not over conservative.

\section{CONCLUSION}

From the study the conclusion can be drawn as follows:

1. The proposed confinement designs with considering shear effect are proposed,

2. The utilizations of high-strength steel for confinement were limited up to $800 \mathrm{MPa}$ in the proposed confinement design,

3. The data point comparison between other confinement codes and the proposed model, showed that the proposed model provides better performance from the other models.

\section{AKNOWLEDGEMENTS}

This research was funded by Penelitian Doktor Baru Dana PNBP Institut Teknologi Sepuluh Nopember.

\section{REFERENCES}

[1] J. A. Blume, N. M. Newmark, and L. H. Corning, "Design of multistory reinforced concrete buildings for earthquake motions," 1961.

[2] ACI Committee 318, "Building code requirements for structural concrete (ACI 318-11) and commentary," 2011.

[3] R. F.E., A. Brandtzaeg, and R. L. Brown, "A Study of the Failure of Concrete under Combined Compressive Stresses."

[4] ACI Committee 318, "Building code requirements for structural concrete (ACI 318-14) and commentary," 2014.

[5] CSA Committee A23.3, "Design of concrete structures (CSA A23.3-04)," 2004

[6] NZS Committee P 3101, "Concrete structures standard - the design of concrete structures (NZS3101 Part 1)," Wellington, 2006.

[7] ACI ITG-4.3R-07, "Report on structural design and detailing for high-strength concrete in moderate to high seismic applications," 2008.

[8] K. J. Elwood, J. Maffei, K. A. Riederer, and K. Telleen, "Improving column confinement, part 1: assessment of design provisions," Concr. Int., vol. 31, no. 11, pp. 32-39, 2009.

[9] Pujol, Santiago., Sozen, Mete., and Ramirez, Julio. "Transverse reinforcement for columns of RC frames to resist earthquakes", ASCE, 2000

[10] Coulomb, C. A., "Essai sur une Application des Re`gles de Maximis et Minimis a` quelques Proble`mes de Statique Relatifs a` l'Architecture", Proc., l'Acade'mie Royale des Sciences par divers savans, et lu^s dans ses assemble'es, Me'moires de Mathe'matique et de Physique, Vol. 7, 343-382 (in French), 1773.

[11] Richart, F. E., Brandtzaeg, A., and Brown, R. L., "The failure of plain and spirally reinforced concrete in compression", Bull. No. 190, University of Illinois Engrg. Experiment Station, 26(31), 52 1929. 
The Third International Conference on Civil Engineering Research (ICCER)

August $1^{\text {st }}-2^{\text {nd }} 2017$, Surabaya - Indonesia

[12]ASCE/SEI, Minimum Design Loads for Buildings and Other Structures, American Society of Civil Engineers, Reston, VA, 2006. 